\title{
Energy dependence of effective atomic numbers for photon energy absorption of vitamins
}

\author{
Anil Shantappa ${ }^{1}$, Shivraj G. Gounhalli ${ }^{2}$, S. M. Hanagodimath ${ }^{3}$ \\ ${ }^{1,2,3}$ Department of Physics, Gulbarga University, Gulbarga 585 106, Karnataka, India
}

\begin{abstract}
Mass - Energy absorption coefficient, Effective atomic numbers for photon energy absorption $\left(Z_{P E A, e f f}\right)$ and photon interactions $\left(Z_{P I, \text { eff }}\right)$, of 8 Vitamins viz., vitamin-A (Retinol), B2 (Riboflavin), B3 (Niacin), $B 7$ (Biotin), B9 (Folic acid), B12 (Cobalamin), K1 (Phylloquinone) and P (Flavonoids) were computed for the energy range $1 \mathrm{keV}$ to $20 \mathrm{MeV}$. Variation of these parameters has been studied as a function of incident photon energy. The $Z_{P E A, e f f}$ and $Z_{P I, e f f}$ values have been found to change with energy and composition of the biological molecules. The variations of mass energy-absorption coefficient, effective atomic number for photon interaction $Z_{P I, \text { eff }}$ and $Z_{P E A, \text { eff }}$ with energy are shown graphically. The substantial deviation occurs among $Z_{P E A, \text { eff }}$ and $Z_{P I, \text { eff }}$ in the energy range 5-100 keV for Retinol and Phylloquinone. The deviation is also observed for Riboflavin, Niacin, Folic acid, Flavonoids in the energy range $8-100 \mathrm{keV}$, and for Biotin (15-150 keV) and for Cobalamin (6-200 keV). The substantial change occurs between $Z_{P E A, \text { eff }}$ and $Z_{P I, e f f}$ which represents the absorbed dose, it is preferable to use $Z_{P E A, \text { eff }}$ instead of $Z_{P I, e f f}$ in medical radiation dosimetry for the calculation of absorbed dose in radiation therapy
\end{abstract}

Keywords: Absorption edges; Absorbed dose; Biological molecules; Effective atomic numbers; Mass-Energy absorption coefficient; Vitamins

\section{Introduction}

The amount of energy that is actually deposited in the medium is important in evaluating biological effects, explaining the response of a radiation detector and other applications. For this purpose, one can define a linear energy-absorption coefficient, $\mu_{\mathrm{en}}$. This coefficient includes only the energy absorbed in the medium from photoelectrons, Compton electrons and the electron-positron pair. But, energy carried away by scattered Compton photons, annihilation radiation and bremsstrahlung radiation is not included.

A more detailed version of the energy-deposition quantity is the mass energy-absorption coefficient, $\mu_{\mathrm{en}} / \rho$, and can be described more clearly through the use of intermediate quantity called mass energy- transfer coefficient. Mass energy-transfer coefficient, $\mu_{\mathrm{tr}} / \rho$, is the mass attenuation coefficient multiplied by the fraction of energy of the interacting photons which is transferred to charged particles as kinetic energy. Hence, $\mu_{\mathrm{tr}} / \rho$ is a measure of the average fractional amount of incident photon energy transferred to charged particles as kinetic energy due to all types of interaction of photons with matter.

The mass energy-absorption coefficient, $\mu_{\mathrm{en}} / \rho$, takes into account the fraction of the kinetic energy that is subsequently lost in radiative energy loss processes as the charged particles slow down to rest in the absorbing medium. The net kinetic energy of charged particles is in turn, a more or less valid approximation to the amount of photon energy made available for the production of chemical, biological and other effects associated with exposure to ionizing radiation. Therefore $\mu_{\mathrm{en}} / \rho$ has an essential role in estimating the absorbed dose in medical and health physics. The $\mu / \rho$ and $\mu_{\mathrm{en}} / \rho$ are basic quantity used in calculation of the penetration and the energy deposition by photons in biological, shielding and other materials [1].

Various researchers [2-10] carried out broad investigation on $\mathrm{Z}_{\mathrm{PI}, \text { eff }}$ in a variety of composite materials like alloys, polymers, thermoluminescent and dosimetric compounds, semiconductors, superconductors, tissues, and equivalent materials for photon interaction. Corresponding studies for $Z_{\mathrm{PEA} \text {,eff }}$ appear to be limited ${ }^{[11-14]}$. In the literature, there are no reports on the study of $Z_{\mathrm{PEA} \text {,eff }}$ of selected vitamins. This inspired us to carry out the present work. In the present work, the $\mathrm{Z}_{\mathrm{PEA} \text {,eff }}$ has been calculated for selected vitamins namely Vitamin-A (Retinol), B2 (Riboflavin), B3 (Niacin), B7 (Biotin), B9 (Folic acid), B12 (Cobalamin), K1 (Phylloquinone) and $\mathrm{P}$ (Flavonoids) by a direct method in the energy region of $1 \mathrm{keV}$ to $20 \mathrm{MeV}$ using the $\mu_{\mathrm{en}} / \rho$ values from the compilation of Hubbell and Seltzer ${ }^{1}$. The $Z_{\mathrm{PEA} \text {,eff }}$ and $Z_{\mathrm{PI} \text {,eff }}$ values have been found to change with energy and composition of the vitamins. The variations of $Z_{\mathrm{PEA}, \text { eff }}$ and $Z_{\mathrm{PI}, \text { eff }}$ with energy are shown graphically. The reasons for using $Z_{\mathrm{PEA} \text {,eff }}$ rather than the commonly used $Z_{\mathrm{PI}, \text { eff }}$ in medical radiation dosimetry for the calculation of absorbed dose in radiation therapy are discussed. The effect of absorption edge on $Z_{\mathrm{PEA} \text {, eff }}$ and its variation with photon energy and the possibility of defining two set values of these parameters below the K-absorption edge of high-Z element present in the Biotin and cobalamin are discussed. 


\section{Theoretical Basis.}

The effective atomic number for photon-energy absorption can be obtained by using mass energyabsorption coefficients of the vitamins. The values of mass energy-absorption coefficients of vitamins, $\mu_{\mathrm{en}} / \rho$, are evaluated using the additivity law [11]:

$$
\left(\frac{\mu_{e n}}{\rho}\right)=\sum_{i} w_{i}\left(\frac{\mu_{e n}}{\rho}\right)_{i}
$$

where $w_{i}$ and $\left(\mu_{\mathrm{en}} / \rho\right)_{\mathrm{i}}$ are the weight fraction and mass energy- absorption coefficients of the $i^{\text {th }}$ constituent element, respectively. The $\mu_{\mathrm{en}} / \rho$ values of the constituent elements of the vitamins are taken from compilation of Hubbell and Seltzer ${ }^{15}$.

The $\left(\mu_{\mathrm{en}} / \rho\right)$ values were then used to determine the total molecular energy-absorption cross-section $\left(\sigma_{\mathrm{m}, \mathrm{e}}\right)$ by the following relation:

$$
\sigma_{m, e n}=\frac{M}{N_{A}}\left(\frac{\mu_{e n}}{\rho}\right)
$$

where $\quad M=\sum_{i} n_{i} A_{i}$ is the molecular weight of the vitamins, $\mathrm{N}_{\mathrm{A}}$ is the Avogadro's number, $\mathrm{n}_{\mathrm{i}}$ is the total number of atoms in the molecule, $A_{i}$ is the atomic weight of the $i^{\text {th }}$ element in a molecule.

The effective (average) atomic energy-absorption cross-section $\left(\sigma_{\text {a.en }}\right)$ can be determined from the following equation:

$$
\sigma_{a, e n}=\sum_{i} f_{i} A_{i}\left(\frac{\mu_{e n}}{\rho}\right)_{i}=\frac{\sigma_{m, e n}}{\sum_{i} n_{i}}
$$

where $f_{i}=n_{i} / \sum_{j} n_{j}$ is the fractional abundance of constituent element, ' $\mathrm{n}_{\mathrm{i}}$ ' is the total number of atoms of the constituent element, is the total number of atoms present in the molecular formula.

Similarly, effective electronic energy-absorption cross-section $\left(\sigma_{\mathrm{e}, \mathrm{en}}\right)$ is given by:

$$
\sigma_{e, e n}=\frac{1}{N_{A}} \sum_{i} \frac{f_{i} A_{i}}{Z_{i}}\left(\frac{\mu_{e n}}{\rho}\right)_{i}=\frac{\sigma_{a, e n}}{Z_{P E A, e f f}}
$$

where $Z_{\mathrm{i}}$ is the atomic number of constituent element. Now, the effective atomic number for photonenergy absorption can be given as:

$$
Z_{P E A, e f f}=\frac{\sigma_{a, e n}}{\sigma_{e, e n}}
$$

3) Figures and Tables

3.1) Figures

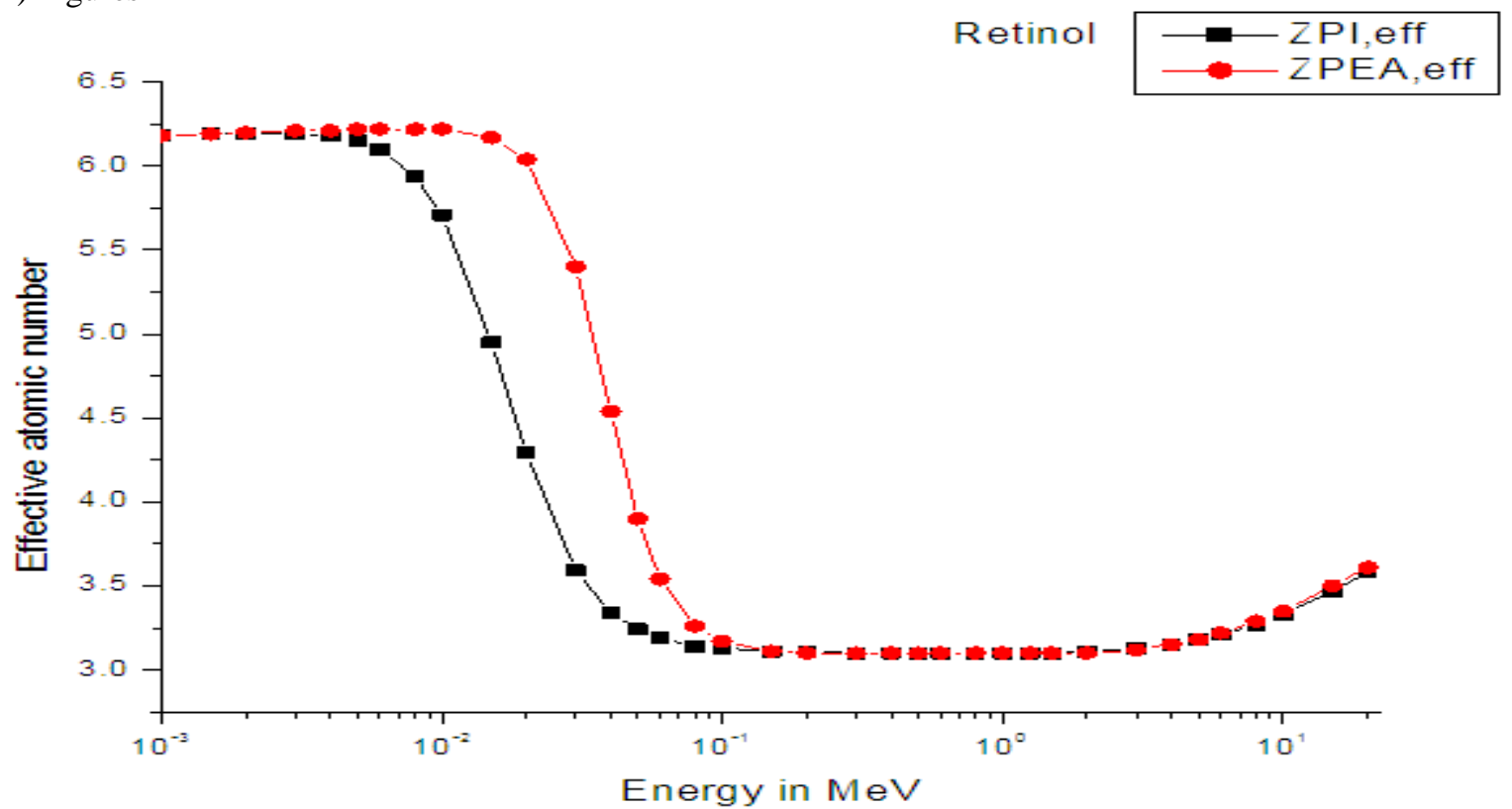

Fig.1. Variation of effective atomic number for photon energy absorption $\left(Z_{\mathrm{PEA}, \text { eff }}\right)$ and effective atomic number for photon interaction ( $\mathrm{Z}_{\mathrm{PI}, \mathrm{eff}}$ ) with photon energy for Retinol. 


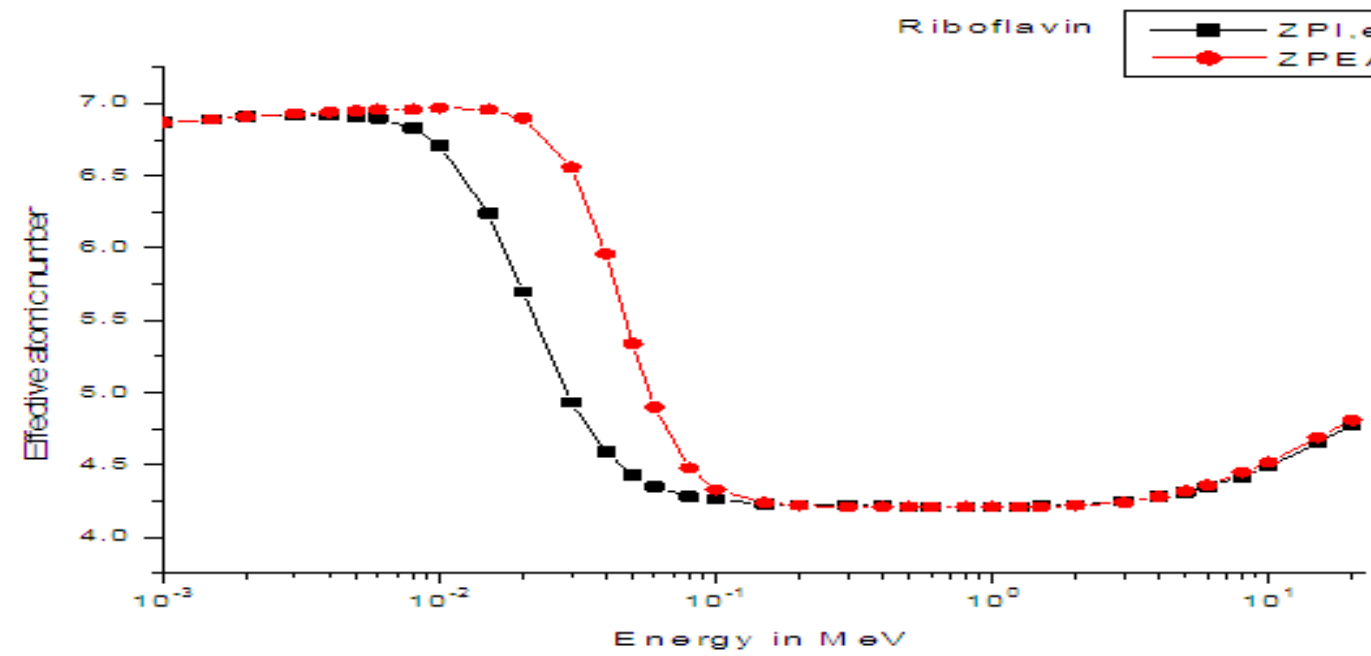

Fig.2. Variation of effective atomic number for photon energy absorption ( $\left.Z_{\mathrm{PEA}, \mathrm{eff}}\right)$ and effective atomic number for photon interaction $\left(\mathrm{Z}_{\mathrm{PI}, \text { eff }}\right)$ with photon energy for Riboflavin.

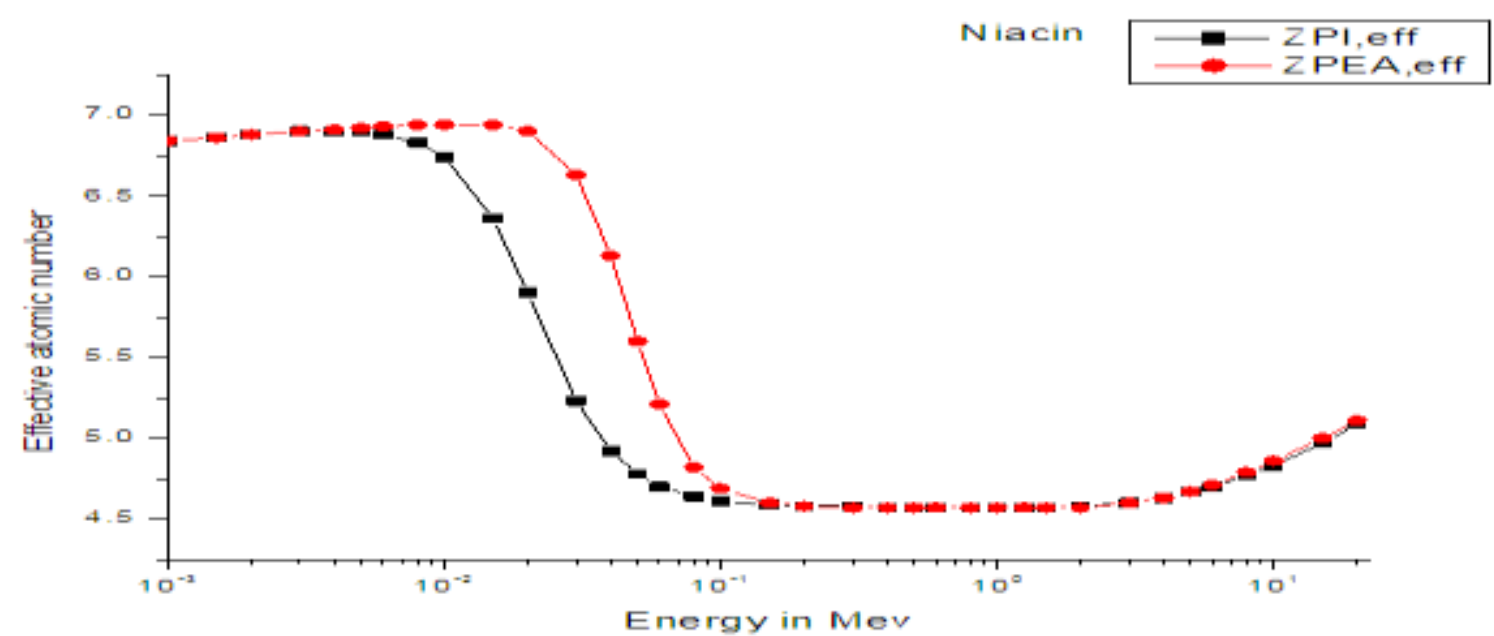

Fig.3. Variation of effective atomic number for photon energy absorption $\left(Z_{\mathrm{PEA}, \mathrm{eff}}\right)$ and effective atomic number for photon interaction $\left(\mathrm{Z}_{\mathrm{PI}, \mathrm{eff}}\right)$ with photon energy for Niacin.

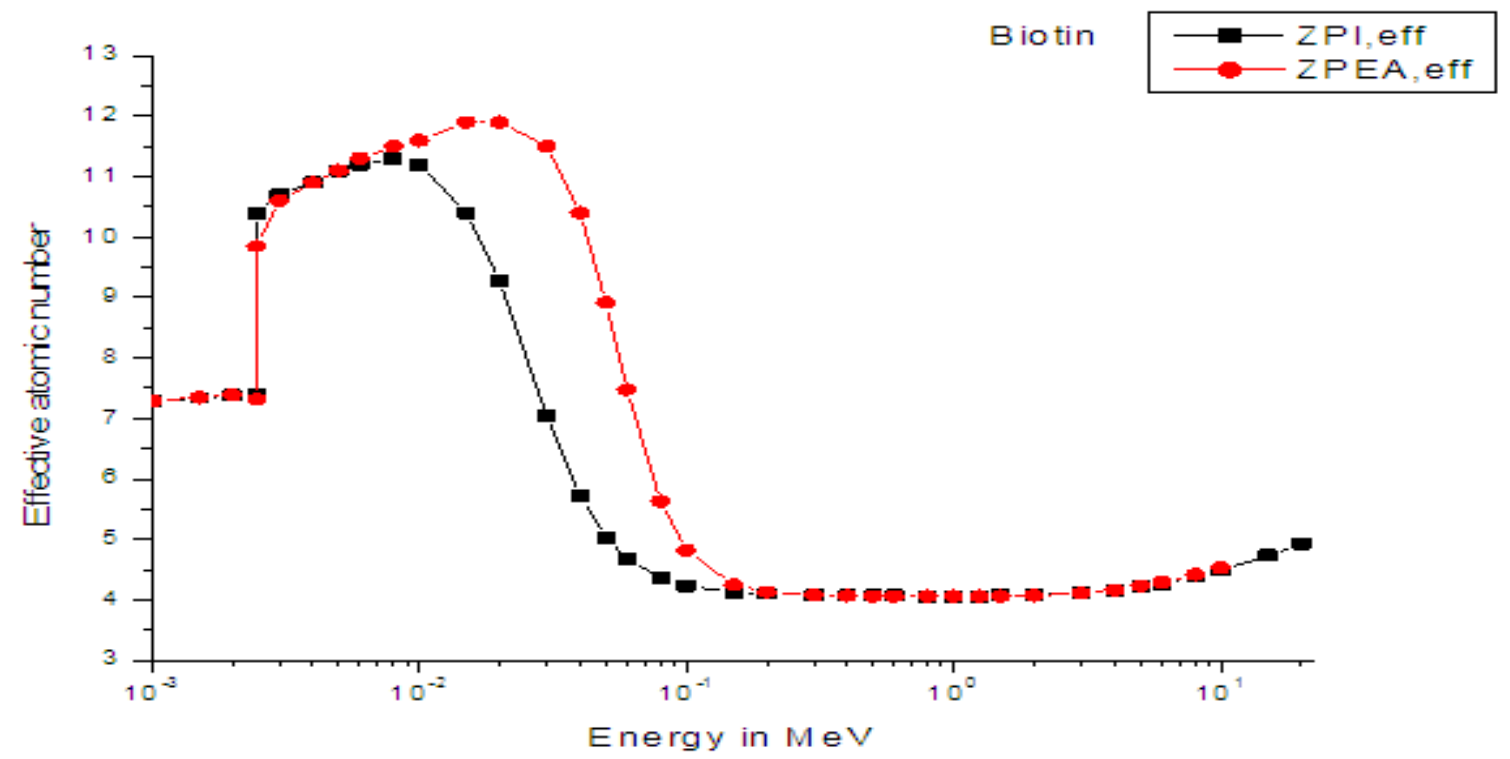

Fig.4. Variation of effective atomic number for photon energy absorption $\left(Z_{\mathrm{PEA}, \mathrm{eff}}\right)$ and effective atomic number for photon interaction $\left(\mathrm{Z}_{\mathrm{PI}, \mathrm{eff}}\right)$ with photon energy for Biotin. 


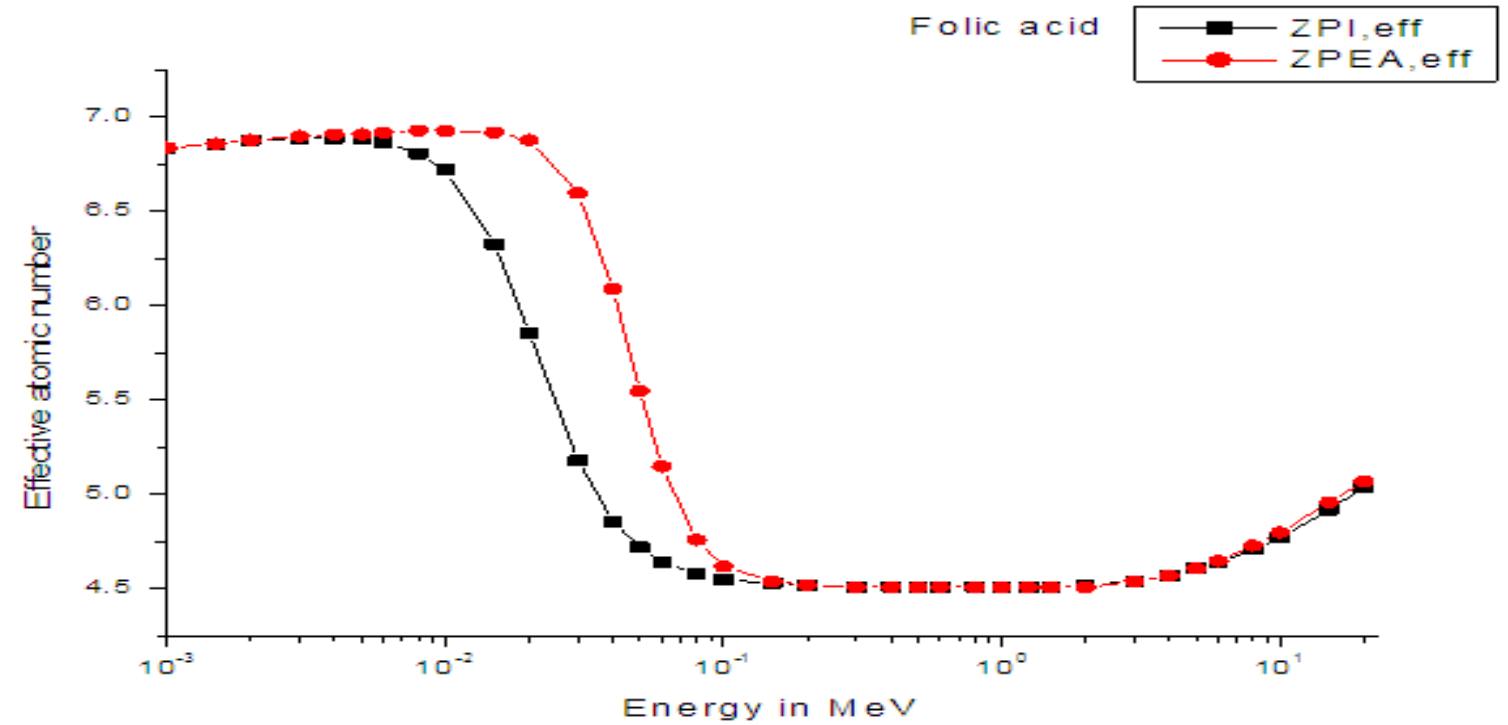

Fig.5. Variation of effective atomic number for photon energy absorption ( $\left.Z_{\mathrm{PEA}, \text { eff }}\right)$ and effective atomic number for photon interaction $\left(\mathrm{Z}_{\mathrm{P}, \mathrm{eff}}\right)$ with photon energy for Folic acid.

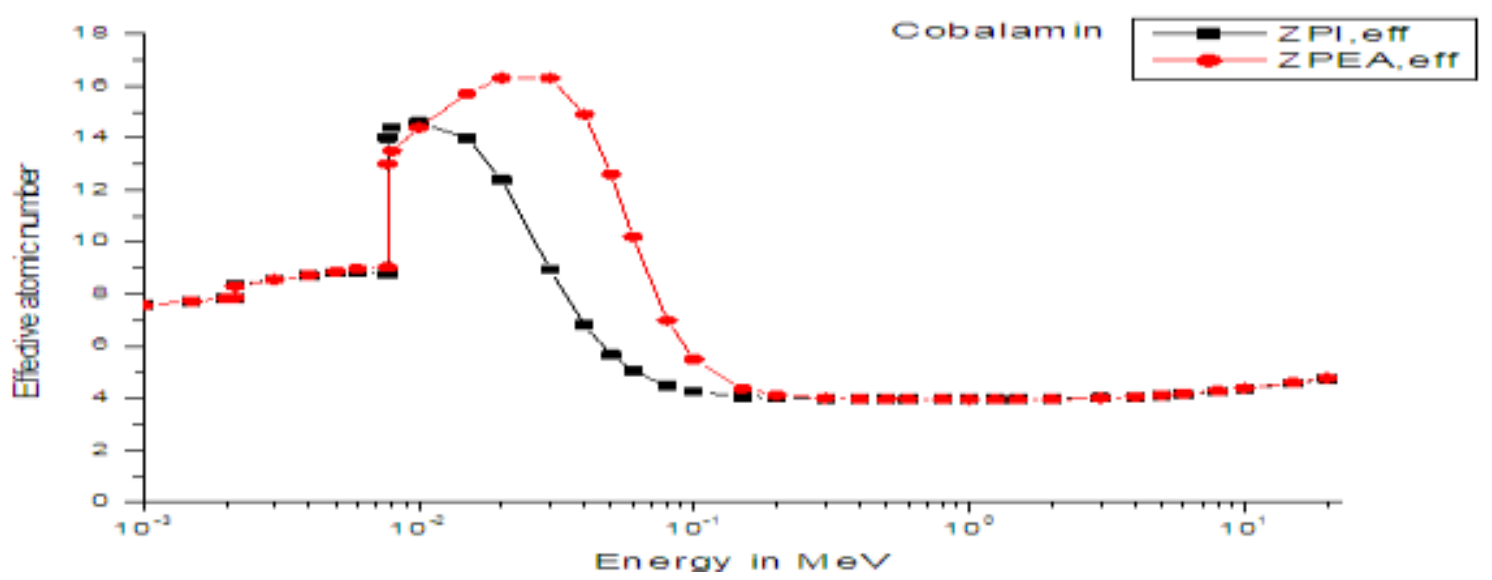

Fig.6. Variation of effective atomic number for photon energy absorption ( $Z_{\mathrm{PEA}, \text { eff }}$ ) and effective atomic number for photon interaction $\left(\mathrm{Z}_{\mathrm{PI}, \mathrm{eff}}\right)$ with photon energy for Cobalamin.

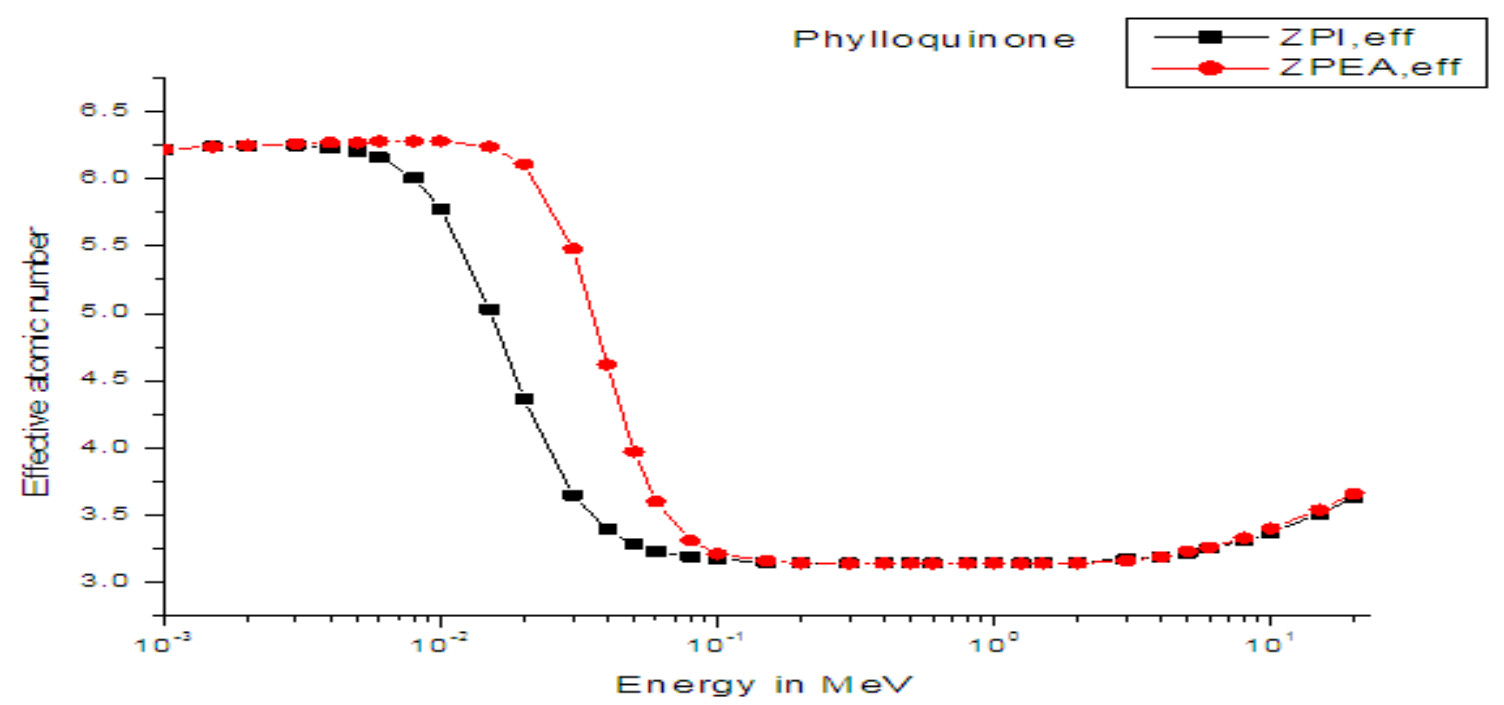

Fig.7. Variation of effective atomic number for photon energy absorption ( $\left.Z_{\mathrm{PEA}, \text { eff }}\right)$ and effective atomic number for photon interaction $\left(\mathrm{Z}_{\mathrm{PI}, \mathrm{eff}}\right)$ with photon energy for Phylloquinone. 


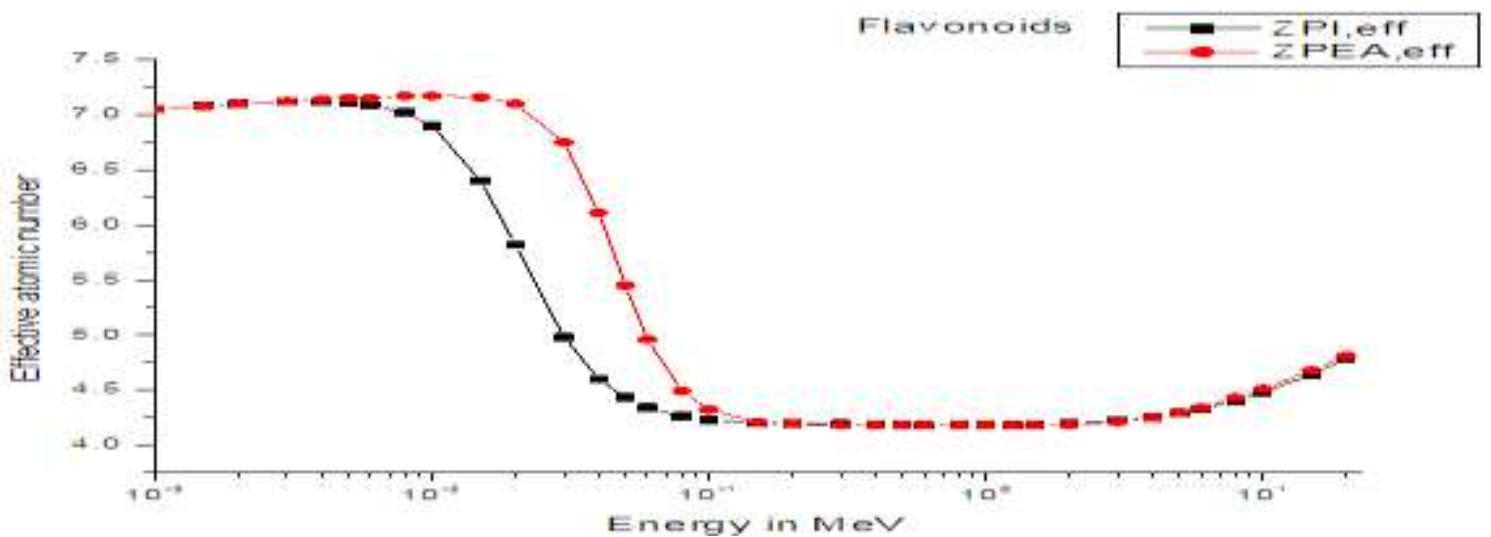

Fig.8. Variation of effective atomic number for photon energy absorption ( $Z_{\mathrm{PEA}, \text { eff }}$ ) and effective atomic number for photon interaction $\left(\mathrm{Z}_{\mathrm{PI}, \mathrm{eff}}\right)$ with photon energy for Flavonoids.

3.2) Tables

Table. 1 The Vitamin name, chemical name and molecular formula of selected vitamins

\begin{tabular}{|c|c|c|}
\hline Vitamin name & Chemical name & Molecular formula \\
\hline Vitamin A & Retinol & $\mathrm{C}_{20} \mathrm{H}_{30} \mathrm{O}$ \\
\hline Vitamin B2 & Riboflavin & $\mathrm{C}_{17} \mathrm{H}_{20} \mathrm{~N}_{4} \mathrm{O}_{6}$ \\
\hline Vitamin B3 & Niacin & $\mathrm{C}_{6} \mathrm{H}_{5} \mathrm{NO}_{2}$ \\
\hline Vitamin B7 & Biotin & $\mathrm{C}_{10} \mathrm{H}_{16} \mathrm{~N}_{2} \mathrm{O}_{3} \mathrm{~S}$ \\
\hline Vitamin B9 & Folic acid & $\mathrm{C}_{19} \mathrm{H}_{19} \mathrm{~N}_{7} \mathrm{O}_{6}$ \\
\hline Vitamin B12 & Cobalamin & $\mathrm{C}_{63} \mathrm{H}_{88} \mathrm{~N}_{14} \mathrm{O}_{14} \mathrm{CoP}$ \\
\hline Vitamin K1 & Phylloquinone & $\mathrm{C}_{31} \mathrm{H}_{46} \mathrm{O}_{2}$ \\
\hline Vitamin P & Flavonoids & $\mathrm{C}_{28} \mathrm{H}_{34} \mathrm{O}_{15}$ \\
\hline
\end{tabular}

Table.2.a Effective atomic number of selected vitamins for photon energy absorption

\begin{tabular}{|c|c|c|c|c|c|c|}
\hline $\begin{array}{l}\text { Energy } \\
(\mathrm{MeV})\end{array}$ & Retinol & Riboflavin & Niacin & Folic acid & $\begin{array}{c}\text { Phylloquino } \\
\text { ne }\end{array}$ & Flavonoids \\
\hline $1.00 \mathrm{E}-03$ & $6.18 \mathrm{E}+00$ & $6.87 \mathrm{E}+00$ & $6.84 \mathrm{E}+00$ & $6.84 \mathrm{E}+00$ & $6.22 \mathrm{E}+00$ & $7.05 \mathrm{E}+00$ \\
\hline $1.50 \mathrm{E}-03$ & $6.19 \mathrm{E}+00$ & $6.89 \mathrm{E}+00$ & $6.86 \mathrm{E}+00$ & $6.86 \mathrm{E}+00$ & $6.24 \mathrm{E}+00$ & $7.08 \mathrm{E}+00$ \\
\hline $2.00 \mathrm{E}-03$ & $6.20 \mathrm{E}+00$ & $6.91 \mathrm{E}+00$ & $6.88 \mathrm{E}+00$ & $6.88 \mathrm{E}+00$ & $6.25 \mathrm{E}+00$ & $7.10 \mathrm{E}+00$ \\
\hline $3.00 \mathrm{E}-03$ & $6.21 \mathrm{E}+00$ & $6.93 \mathrm{E}+00$ & $6.90 \mathrm{E}+00$ & $6.90 \mathrm{E}+00$ & $6.26 \mathrm{E}+00$ & $7.12 \mathrm{E}+00$ \\
\hline $4.00 \mathrm{E}-03$ & $6.21 \mathrm{E}+00$ & $6.94 \mathrm{E}+00$ & $6.91 \mathrm{E}+00$ & $6.91 \mathrm{E}+00$ & $6.27 \mathrm{E}+00$ & $7.14 \mathrm{E}+00$ \\
\hline $5.00 \mathrm{E}-03$ & $6.22 \mathrm{E}+00$ & $6.95 \mathrm{E}+00$ & $6.92 \mathrm{E}+00$ & $6.91 \mathrm{E}+00$ & $6.27 \mathrm{E}+00$ & $7.15 \mathrm{E}+00$ \\
\hline $6.00 \mathrm{E}-03$ & $6.22 \mathrm{E}+00$ & $6.96 \mathrm{E}+00$ & $6.93 \mathrm{E}+00$ & $6.92 \mathrm{E}+00$ & $6.28 \mathrm{E}+00$ & $7.15 \mathrm{E}+00$ \\
\hline 8.00E-03 & $6.22 \mathrm{E}+00$ & $6.96 \mathrm{E}+00$ & $6.94 \mathrm{E}+00$ & $6.93 \mathrm{E}+00$ & $6.28 \mathrm{E}+00$ & $7.17 \mathrm{E}+00$ \\
\hline $1.00 \mathrm{E}-02$ & $6.22 \mathrm{E}+00$ & $6.97 \mathrm{E}+00$ & $6.94 \mathrm{E}+00$ & $6.93 \mathrm{E}+00$ & $6.28 \mathrm{E}+00$ & $7.17 \mathrm{E}+00$ \\
\hline $1.50 \mathrm{E}-02$ & $6.17 \mathrm{E}+00$ & $6.96 \mathrm{E}+00$ & $6.94 \mathrm{E}+00$ & $6.92 \mathrm{E}+00$ & $6.24 \mathrm{E}+00$ & $7.16 \mathrm{E}+00$ \\
\hline $2.00 \mathrm{E}-02$ & $6.04 \mathrm{E}+00$ & $6.90 \mathrm{E}+00$ & $6.90 \mathrm{E}+00$ & $6.88 \mathrm{E}+00$ & $6.11 \mathrm{E}+00$ & $7.10 \mathrm{E}+00$ \\
\hline $3.00 \mathrm{E}-02$ & $5.40 \mathrm{E}+00$ & $6.56 \mathrm{E}+00$ & $6.63 \mathrm{E}+00$ & $6.60 \mathrm{E}+00$ & $5.48 \mathrm{E}+00$ & $6.75 \mathrm{E}+00$ \\
\hline 4.00E-02 & $4.54 \mathrm{E}+00$ & $5.96 \mathrm{E}+00$ & $6.13 \mathrm{E}+00$ & $6.09 \mathrm{E}+00$ & $4.62 \mathrm{E}+00$ & $6.11 \mathrm{E}+00$ \\
\hline $5.00 \mathrm{E}-02$ & $3.90 \mathrm{E}+00$ & $5.34 \mathrm{E}+00$ & $5.60 \mathrm{E}+00$ & $5.55 \mathrm{E}+00$ & $3.97 \mathrm{E}+00$ & $5.45 \mathrm{E}+00$ \\
\hline $6.00 \mathrm{E}-02$ & $3.54 \mathrm{E}+00$ & $4.90 \mathrm{E}+00$ & $5.21 \mathrm{E}+00$ & $5.15 \mathrm{E}+00$ & $3.60 \mathrm{E}+00$ & $4.96 \mathrm{E}+00$ \\
\hline 8.00E-02 & $3.26 \mathrm{E}+00$ & $4.48 \mathrm{E}+00$ & $4.82 \mathrm{E}+00$ & $4.76 \mathrm{E}+00$ & $3.31 \mathrm{E}+00$ & $4.49 \mathrm{E}+00$ \\
\hline $1.00 \mathrm{E}-01$ & $3.17 \mathrm{E}+00$ & $4.33 \mathrm{E}+00$ & $4.69 \mathrm{E}+00$ & $4.62 \mathrm{E}+00$ & $3.21 \mathrm{E}+00$ & $4.32 \mathrm{E}+00$ \\
\hline $1.50 \mathrm{E}-01$ & $3.11 \mathrm{E}+00$ & $4.24 \mathrm{E}+00$ & $4.60 \mathrm{E}+00$ & $4.54 \mathrm{E}+00$ & $3.16 \mathrm{E}+00$ & $4.21 \mathrm{E}+00$ \\
\hline $2.00 \mathrm{E}-01$ & $3.10 \mathrm{E}+00$ & $4.22 \mathrm{E}+00$ & $4.58 \mathrm{E}+00$ & $4.52 \mathrm{E}+00$ & $3.14 \mathrm{E}+00$ & $4.19 \mathrm{E}+00$ \\
\hline $3.00 \mathrm{E}-01$ & $3.10 \mathrm{E}+00$ & $4.21 \mathrm{E}+00$ & $4.57 \mathrm{E}+00$ & $4.51 \mathrm{E}+00$ & $3.14 \mathrm{E}+00$ & $4.18 \mathrm{E}+00$ \\
\hline $4.00 \mathrm{E}-01$ & $3.10 \mathrm{E}+00$ & $4.21 \mathrm{E}+00$ & $4.57 \mathrm{E}+00$ & $4.51 \mathrm{E}+00$ & $3.14 \mathrm{E}+00$ & $4.18 \mathrm{E}+00$ \\
\hline $5.00 \mathrm{E}-01$ & $3.10 \mathrm{E}+00$ & $4.21 \mathrm{E}+00$ & $4.57 \mathrm{E}+00$ & $4.51 \mathrm{E}+00$ & $3.14 \mathrm{E}+00$ & $4.18 \mathrm{E}+00$ \\
\hline $6.00 \mathrm{E}-01$ & $3.10 \mathrm{E}+00$ & $4.21 \mathrm{E}+00$ & $4.57 \mathrm{E}+00$ & $4.51 \mathrm{E}+00$ & $3.14 \mathrm{E}+00$ & $4.18 \mathrm{E}+00$ \\
\hline
\end{tabular}


Energy dependence of effective atomic numbers for photon energy absorption of vitamins

\begin{tabular}{|c|c|c|c|c|c|c|}
\hline $8.00 \mathrm{E}-01$ & $3.10 \mathrm{E}+00$ & $4.21 \mathrm{E}+00$ & $4.57 \mathrm{E}+00$ & $4.51 \mathrm{E}+00$ & $3.14 \mathrm{E}+00$ & $4.18 \mathrm{E}+00$ \\
$1.00 \mathrm{E}+00$ & $3.10 \mathrm{E}+00$ & $4.21 \mathrm{E}+00$ & $4.57 \mathrm{E}+00$ & $4.51 \mathrm{E}+00$ & $3.14 \mathrm{E}+00$ & $4.18 \mathrm{E}+00$ \\
$1.25 \mathrm{E}+00$ & $3.10 \mathrm{E}+00$ & $4.21 \mathrm{E}+00$ & $4.57 \mathrm{E}+00$ & $4.51 \mathrm{E}+00$ & $3.14 \mathrm{E}+00$ & $4.18 \mathrm{E}+00$ \\
$1.50 \mathrm{E}+00$ & $3.10 \mathrm{E}+00$ & $4.21 \mathrm{E}+00$ & $4.57 \mathrm{E}+00$ & $4.51 \mathrm{E}+00$ & $3.14 \mathrm{E}+00$ & $4.18 \mathrm{E}+00$ \\
$2.00 \mathrm{E}+00$ & $3.10 \mathrm{E}+00$ & $4.22 \mathrm{E}+00$ & $4.57 \mathrm{E}+00$ & $4.51 \mathrm{E}+00$ & $3.14 \mathrm{E}+00$ & $4.18 \mathrm{E}+00$ \\
$3.00 \mathrm{E}+00$ & $3.12 \mathrm{E}+00$ & $4.24 \mathrm{E}+00$ & $4.60 \mathrm{E}+00$ & $4.54 \mathrm{E}+00$ & $3.16 \mathrm{E}+00$ & $4.21 \mathrm{E}+00$ \\
$4.00 \mathrm{E}+00$ & $3.15 \mathrm{E}+00$ & $4.28 \mathrm{E}+00$ & $4.63 \mathrm{E}+00$ & $4.57 \mathrm{E}+00$ & $3.19 \mathrm{E}+00$ & $4.25 \mathrm{E}+00$ \\
$5.00 \mathrm{E}+00$ & $3.18 \mathrm{E}+00$ & $4.32 \mathrm{E}+00$ & $4.67 \mathrm{E}+00$ & $4.61 \mathrm{E}+00$ & $3.23 \mathrm{E}+00$ & $4.30 \mathrm{E}+00$ \\
$6.00 \mathrm{E}+00$ & $3.22 \mathrm{E}+00$ & $4.36 \mathrm{E}+00$ & $4.71 \mathrm{E}+00$ & $4.65 \mathrm{E}+00$ & $3.26 \mathrm{E}+00$ & $4.34 \mathrm{E}+00$ \\
$8.00 \mathrm{E}+00$ & $3.29 \mathrm{E}+00$ & $4.45 \mathrm{E}+00$ & $4.79 \mathrm{E}+00$ & $4.73 \mathrm{E}+00$ & $3.33 \mathrm{E}+00$ & $4.43 \mathrm{E}+00$ \\
$1.00 \mathrm{E}+01$ & $3.35 \mathrm{E}+00$ & $4.52 \mathrm{E}+00$ & $4.86 \mathrm{E}+00$ & $4.80 \mathrm{E}+00$ & $3.40 \mathrm{E}+00$ & $4.51 \mathrm{E}+00$ \\
$1.50 \mathrm{E}+01$ & $3.50 \mathrm{E}+00$ & $4.69 \mathrm{E}+00$ & $5.00 \mathrm{E}+00$ & $4.96 \mathrm{E}+00$ & $3.54 \mathrm{E}+00$ & $4.68 \mathrm{E}+00$ \\
$2.00 \mathrm{E}+01$ & $3.61 \mathrm{E}+00$ & $4.81 \mathrm{E}+00$ & $5.11 \mathrm{E}+00$ & $5.07 \mathrm{E}+00$ & $3.66 \mathrm{E}+00$ & $4.81 \mathrm{E}+00$ \\
\hline
\end{tabular}

Table.2.b Effective atomic number of selected vitamins for photon energy absorption

\begin{tabular}{|c|c|c|c|}
\hline Energy(MeV) & Biotin & Energy(MeV) & Cobalamin \\
\hline $1.00 \mathrm{E}-03$ & $7.29 \mathrm{E}+00$ & $1.00 \mathrm{E}-03$ & $7.58 \mathrm{E}+00$ \\
$1.50 \mathrm{E}-03$ & $7.35 \mathrm{E}+00$ & $1.50 \mathrm{E}-03$ & $7.73 \mathrm{E}+00$ \\
$2.00 \mathrm{E}-03$ & $7.39 \mathrm{E}+00$ & $2.00 \mathrm{E}-03$ & $7.84 \mathrm{E}+00$ \\
$2.47 \mathrm{E}-03$ & $7.32 \mathrm{E}+00$ & $2.15 \mathrm{E}-03$ & $7.86 \mathrm{E}+00$ \\
$2.47 \mathrm{E}-03$ & $9.85 \mathrm{E}+00$ & $2.15 \mathrm{E}-03$ & $8.30 \mathrm{E}+00$ \\
$3.00 \mathrm{E}-03$ & $1.06 \mathrm{E}+01$ & $3.00 \mathrm{E}-03$ & $8.56 \mathrm{E}+00$ \\
$4.00 \mathrm{E}-03$ & $1.09 \mathrm{E}+01$ & $4.00 \mathrm{E}-03$ & $8.73 \mathrm{E}+00$ \\
$5.00 \mathrm{E}-03$ & $1.11 \mathrm{E}+01$ & $5.00 \mathrm{E}-03$ & $8.87 \mathrm{E}+00$ \\
$6.00 \mathrm{E}-03$ & $1.13 \mathrm{E}+01$ & $6.00 \mathrm{E}-03$ & $8.98 \mathrm{E}+00$ \\
$8.00 \mathrm{E}-03$ & $1.15 \mathrm{E}+01$ & $7.71 \mathrm{E}-03$ & $9.03 \mathrm{E}+00$ \\
$1.00 \mathrm{E}-02$ & $1.16 \mathrm{E}+01$ & $7.71 \mathrm{E}-03$ & $1.30 \mathrm{E}+01$ \\
$1.50 \mathrm{E}-02$ & $1.19 \mathrm{E}+01$ & $8.00 \mathrm{E}-03$ & $1.35 \mathrm{E}+01$ \\
$2.00 \mathrm{E}-02$ & $1.19 \mathrm{E}+01$ & $1.00 \mathrm{E}-02$ & $1.44 \mathrm{E}+01$ \\
$3.00 \mathrm{E}-02$ & $1.15 \mathrm{E}+01$ & $1.50 \mathrm{E}-02$ & $1.57 \mathrm{E}+01$ \\
$4.00 \mathrm{E}-02$ & $1.04 \mathrm{E}+01$ & $2.00 \mathrm{E}-02$ & $1.63 \mathrm{E}+01$ \\
$5.00 \mathrm{E}-02$ & $8.92 \mathrm{E}+00$ & $3.00 \mathrm{E}-02$ & $1.63 \mathrm{E}+01$ \\
$6.00 \mathrm{E}-02$ & $7.48 \mathrm{E}+00$ & $4.00 \mathrm{E}-02$ & $1.49 \mathrm{E}+01$ \\
$8.00 \mathrm{E}-02$ & $5.63 \mathrm{E}+00$ & $5.00 \mathrm{E}-02$ & $1.26 \mathrm{E}+01$ \\
$1.00 \mathrm{E}-01$ & $4.82 \mathrm{E}+00$ & $6.00 \mathrm{E}-02$ & $1.02 \mathrm{E}+01$ \\
$1.50 \mathrm{E}-01$ & $4.25 \mathrm{E}+00$ & $8.00 \mathrm{E}-02$ & $6.99 \mathrm{E}+00$ \\
$2.00 \mathrm{E}-01$ & $4.13 \mathrm{E}+00$ & $1.00 \mathrm{E}-01$ & $5.50 \mathrm{E}+00$ \\
$3.00 \mathrm{E}-01$ & $4.08 \mathrm{E}+00$ & $1.50 \mathrm{E}-01$ & $4.37 \mathrm{E}+00$ \\
$4.00 \mathrm{E}-01$ & $4.07 \mathrm{E}+00$ & $2.00 \mathrm{E}-01$ & $4.12 \mathrm{E}+00$ \\
$5.00 \mathrm{E}-01$ & $4.06 \mathrm{E}+00$ & $3.00 \mathrm{E}-01$ & $4.01 \mathrm{E}+00$ \\
$6.00 \mathrm{E}-01$ & $4.06 \mathrm{E}+00$ & $4.00 \mathrm{E}-01$ & $3.98 \mathrm{E}+00$ \\
$8.00 \mathrm{E}-01$ & $4.06 \mathrm{E}+00$ & $5.00 \mathrm{E}-01$ & $3.97 \mathrm{E}+00$ \\
$1.00 \mathrm{E}+00$ & $4.06 \mathrm{E}+00$ & $6.00 \mathrm{E}-01$ & $3.97 \mathrm{E}+00$ \\
$1.25 \mathrm{E}+00$ & $4.06 \mathrm{E}+00$ & $8.00 \mathrm{E}-01$ & $3.97 \mathrm{E}+00$ \\
$1.50 \mathrm{E}+00$ & $4.06 \mathrm{E}+00$ & $1.00 \mathrm{E}+00$ & $3.96 \mathrm{E}+00$ \\
\hline & & & \\
\hline
\end{tabular}




\begin{tabular}{|l|l|l|l|}
\hline $2.00 \mathrm{E}+00$ & $4.07 \mathrm{E}+00$ & $1.25 \mathrm{E}+00$ & $3.96 \mathrm{E}+00$ \\
$3.00 \mathrm{E}+00$ & $4.11 \mathrm{E}+00$ & $1.50 \mathrm{E}+00$ & $3.96 \mathrm{E}+00$ \\
$4.00 \mathrm{E}+00$ & $4.16 \mathrm{E}+00$ & $2.00 \mathrm{E}+00$ & $3.97 \mathrm{E}+00$ \\
$5.00 \mathrm{E}+00$ & $4.23 \mathrm{E}+00$ & $3.00 \mathrm{E}+00$ & $4.01 \mathrm{E}+00$ \\
$6.00 \mathrm{E}+00$ & $4.29 \mathrm{E}+00$ & $4.00 \mathrm{E}+00$ & $4.06 \mathrm{E}+00$ \\
$8.00 \mathrm{E}+00$ & $4.42 \mathrm{E}+00$ & $5.00 \mathrm{E}+00$ & $4.12 \mathrm{E}+00$ \\
$1.00 \mathrm{E}+01$ & $4.53 \mathrm{E}+00$ & $6.00 \mathrm{E}+00$ & $4.17 \mathrm{E}+00$ \\
$1.50 \mathrm{E}+01$ & $4.77 \mathrm{E}+00$ & $8.00 \mathrm{E}+00$ & $4.29 \mathrm{E}+00$ \\
$2.00 \mathrm{E}+01$ & $4.95 \mathrm{E}+00$ & $1.00 \mathrm{E}+01$ & $4.39 \mathrm{E}+00$ \\
& & $1.50 \mathrm{E}+01$ & $4.61 \mathrm{E}+00$ \\
& & $2.00 \mathrm{E}+01$ & $4.77 \mathrm{E}+00$ \\
\hline
\end{tabular}

\section{Results And Discussion}

In the present work, we computed the $Z_{\text {PEA,eff }}$ with photon energy for selected vitamins consisting of $\mathrm{H}$, $\mathrm{C}, \mathrm{N}, \mathrm{O}, \mathrm{S}, \mathrm{Co}$ and Phosphorous in different proportions were studied. The variations of $\mathrm{Z}_{\mathrm{PEA}, \text { eff }}$ and $\mathrm{Z}_{\mathrm{PI} \text {,eff }}$ with energy are shown in Figs 1-8. The calculated values of $Z_{\text {PEA,eff }}$ by direct method in the energy region of $1 \mathrm{keV}$ to $20 \mathrm{MeV}$ using the $\mu_{\mathrm{en}} / \rho$ values from the compilation of Hubbell and Seltzer ${ }^{1}$ are given in Table. 2.a and 2.b. It can be seen from Figs. 1-8 that the variation of $Z_{\mathrm{PEA}, \text { eff }}$ and $Z_{\mathrm{PI}, \text { eff }}$ with energy is almost similar for all vitamins except Biotin and Cobalamin due to abrupt changes near the absorption edge. For Biotin, there are two values for mass energy-absorption coefficients at $2.47 \mathrm{keV}$ due to the sulfur $\mathrm{K}$ absorption edge. The value $2.15 \times 10^{2} \mathrm{~cm}^{2} / \mathrm{g}$ is valid immediately below the absorption edge, and $1.935 \times 10^{2} \mathrm{~cm}^{2} / \mathrm{g}$ immediately above the absorption edge. The $\mu_{\mathrm{en}} / \rho$ values of all the constituent elements of Biotin are not available in the compilation of Hubbell and Seltzer [1] at $2.47 \mathrm{keV}$. For each of these elements in biotin, the value at $2.47 \mathrm{keV}$ can be found by interpolation. Similarly, the $\mu_{\mathrm{en}} / \rho$ values of all the constituent elements of cobalamin are not available at $2.15 \mathrm{keV}$ and $7.71 \mathrm{keV}$. The cobalamin, which consists of phosphorous and cobalt having absorption edge at $2.15 \mathrm{keV}$ and $7.71 \mathrm{keV}$ respectively. The $\mu_{\mathrm{en}} / \rho$ values can be found by interpolation and using the additivity law [15].

From Figs 1-8 it can be seen that the photon energy absorption $\left(Z_{\mathrm{PEA}, \text { eff }}\right)$ varies with the energy. The gradual increase in $\mathrm{Z}_{\mathrm{PEA} \text {,eff }}$ is observed in the energy range $1 \mathrm{keV}-5 \mathrm{keV}$ for Retinol and Riboflavin and then decreases rapidly from $6 \mathrm{keV}$ to $200 \mathrm{keV}$ then after it remains constant up to $2 \mathrm{MeV}$ and then again increases steadily up to $20 \mathrm{MeV}$. For Niacin and Folic acid the $Z_{\text {PEA,eff }}$ increases slowly from $1 \mathrm{keV}$ to $8 \mathrm{keV}$ and then decreases rapidly up to $200 \mathrm{keV}$ after that it remains constant from $300 \mathrm{keV}$ to $2 \mathrm{MeV}$. Above $3 \mathrm{MeV}$, the value increases with increase in energy up to $20 \mathrm{MeV}$. For Phylloquinone and Flavonoids the $Z_{\text {PEA,eff }}$ increases slowly from $1 \mathrm{keV}$ to $10 \mathrm{keV}$ and then decreases rapidly up to $200 \mathrm{keV}$ after that it remains constant from $300 \mathrm{keV}$ to $2 \mathrm{MeV}$. Above $3 \mathrm{MeV}$, the value increases with increase in energy up to $20 \mathrm{MeV}$. For Biotin and Cobalamin the value of $Z_{\mathrm{PEA} \text {,eff }}$ increases steadily from $1 \mathrm{keV}-20 \mathrm{keV}$ there after decreases immediately up to $500 \mathrm{keV}$ and then remains steady from $600 \mathrm{keV}-2 \mathrm{MeV}$. From $3 \mathrm{MeV}$, the value increases with increase in energy up to $20 \mathrm{MeV}$. The variation of effective atomic number for photon energy absorption $\left(Z_{\text {PEA,eff }}\right)$ is almost same for all vitamins except Biotin and Cobalamin, because of the $\mathrm{K}$ absorption edge of sulfur in Biotin, Cobalt and phosphorous in Cobalamin.

It is observed that the variation in $Z_{\mathrm{PEA}, \text { eff }}$ also depends upon relative proportion and the range of atomic numbers of the elements of which vitamins is composed. The Biotin has a large range of atomic numbers from $1(\mathrm{H})$ to $16(\mathrm{~S})$ and Cobalamin has $1(\mathrm{H})$ to $27(\mathrm{Co})$ than any other vitamins because of which the change of effective atomic number for photon energy absorption with energy is enormously substantial in comparison with other vitamins. The variation of $Z_{\mathrm{PEA} \text {,eff }}$ with energy confirms the dominance of different processes, that is photoelectric absorption, compton scattering, pair production (Nuclear field and electric field). From Fig.4 it is clear that, the value of $Z_{\mathrm{PEA} \text {,eff }} \mathrm{jumps}$ suddenly at $\mathrm{K}$ absorption edge due to sulfur. Similarly for Cobalamin, from Fig. 6 it can be seen that, there is a abrupt change in $Z_{\text {PEA,eff }}$ at absorption edge of high atomic number elements (phosphorous and cobalt). In case of Biotin two set of values of $Z_{\mathrm{PEA}, \text { eff }}$ are possible at $2.47 \mathrm{keV}$ due to the sulfur $\mathrm{K}$ absorption edge. Similarly, in the case of Cobalamin two set of values of $Z_{\mathrm{PEA}, \text { eff }}$ are possible at $2.15 \mathrm{keV}$ and also two set of values at $7.709 \mathrm{keV}$ due to the $\mathrm{K}$ absorption edge of phosphorous and cobalt respectively. The values of $\mathrm{Z}_{\mathrm{PI}, \text { eff }}$ at $\mathrm{K}$ absorption edges of sulfur, phosphorous and cobalt are calculated using the WinXCom[16]. The present theoretical results are in close agreement with the theoretical results of Shivaramu et al [11-13], who have reported similar types of variation of $Z_{\mathrm{PEA} \text {,eff }}$ and $\mathrm{Z}_{\mathrm{PI} \text {,eff }}$ for substances of dosimetric interest, human organs and tissues, and thermoluminescent dosimetric compounds. Similar results were also obtained recently by Manohara and Hanagodimath [14] in some biological molecules. No experimental data on $Z_{\mathrm{PEA} \text {,eff }}$ could be 
obtained for comparison purposes due to the reason that it is not possible to measure $\mu_{\text {en }} / \rho$ experimentally, unlike $\mu / \rho$ which can be easily measured by performing transmission experiments in a narrow beam good geometry set-up using the conventional gamma spectrometry system.

The substantial deviation occurs among $Z_{\mathrm{PEA} \text {,eff }}$ and $\mathrm{Z}_{\mathrm{PI}, \text { eff }}$ in the energy range 5-100 keV for Retinol and Phylloquinone. Similarly $8-100 \mathrm{keV}$ for Riboflavin, Niacin, Folic acid, Flavonoids and 15-150 keV for Biotin and 6-200 keV for Cobalamin. The maximum difference is observed at $30 \mathrm{keV}$ for all the vitamins studied except for Biotin and Cobalamin, for which it is at $40 \mathrm{keV}$. There is a shift in the energy position at which maximum values of $Z_{\mathrm{PEA}, \text { eff }}$ and $Z_{\mathrm{PI}, \text { eff }}$ occur, which can be seen from Figs.1-8. The large percentage of differences occurs among $Z_{\mathrm{PEA} \text {,eff }}$ and $\mathrm{Z}_{\mathrm{PI}, \text { eff }}$ in the $5-100 \mathrm{keV}$ range have a simple physical explanation. $\mathrm{A}$ major part of the Compton scattered radiation escapes the absorbing medium. Thus, while contributing significantly to the attenuation of the incident beam, Compton scattering contributes only a little to the energy absorption. Therefore, the transition from photoelectric absorption to Compton scattering as the dominating absorption process is shifted toward higher energies for the mass energy-absorption coefficient as compared with the mass attenuation coefficient. The substantial change occurs between $Z_{\mathrm{PEA}, \text { eff }}$ and $\mathrm{Z}_{\mathrm{PI} \text {,eff }}$ which represents the absorbed dose, it is preferable to use $Z_{\mathrm{PEA} \text {,eff }}$ instead of $\mathrm{Z}_{\mathrm{PI} \text {,eff }}$ in medical radiation dosimetry for the calculation of absorbed dose in radiation therapy.

\section{Conclusion}

We accounted the results on $Z_{\mathrm{PEA}, \text { eff }}$ which have been calculated by direct method in the energy range $1 \mathrm{keV}$ to $20 \mathrm{MeV}$ for selected vitamins namely Vitamin-A(Retinol), B2 (Riboflavin), B3 (Niacin), B7 (Biotin), $\mathrm{B} 9$ (Folic acid), B12 (Cobalamin), K1 (Phylloquinone) and P (Flavonoids). The $Z_{\mathrm{PEA}, \text { eff }}$ values varies from a higher value at lower energies to a lower value at higher energies with a peak due to photoelectric effect near the $\mathrm{K}$-absorption edge of the high- $\mathrm{Z}$ constituent of the vitamins studied. The substantial deviation occurs among $Z_{\mathrm{PEA}, \text { eff }}$ and $Z_{\mathrm{PI}, \text { eff }}$ in the energy range 5-100 keV for Retinol and Phylloquinone. Similarly $8-100 \mathrm{keV}$ for Riboflavin, Niacin, Folic acid, Flavonoids and $15-150 \mathrm{keV}$ for Biotin and 6-200 keV for Cobalamin. The substantial change occurs between $Z_{\mathrm{PEA}, \text { eff }}$ and $\mathrm{Z}_{\mathrm{PI}, \text { eff }}$ which represents the absorbed dose, it is preferable to use $Z_{\mathrm{PEA}, \text { eff }}$ instead of $Z_{\mathrm{PI}, \text { eff }}$ in medical radiation dosimetry for the calculation of absorbed dose in radiation therapy. It is expected that the new results on $Z_{\mathrm{PEA}, \text { eff }}$ of selected vitamins presented here will be useful in view of their importance in medical dosimetry. To the best of our knowledge, the results reported are the first of their kind and have not been reported earlier.

\section{References:}

[1] J. H. Hubbell, S. M. Seltzer, Tables of X-ray mass attenuation coefficients and mass energy-absorption coefficients $1 \mathrm{keV}-20 \mathrm{MeV}$ for elements $Z=1$ to 92 and 48 additional substances of dosimetric interest, NISTIR 5632, 1995.

[2] R. C. Murty, Effective atomic numbers of heterogeneous materials, Nature London 207, 1965, 398-399.

[3] O. İçelli, S. Erzeneoğlu, İ. H. Karahan, and G. Çankaya, Effective atomic numbers for CoCuNi alloys using transmission experiments, J.Quant. Spectrosc. Radiat. Transf. 91, 2005, 485-491.

[4] N. G. Nayak, M. G. Vijaya, and K. Siddappa, Effective atomic numbers of some polymers and other materials for photoelectric process at $59.54 \mathrm{keV}$, Radiat. Phys. Chem. 61, 2001, 559-561.

[5] Shivaramu, R. Amutha, and V. Ramprasath, Effective atomic numbers and mass attenuation coefficients of some thermoluminescent dosimetric compounds for total photon interaction, Nucl. Sci. Eng. 132, 1999, 148-153.

[6] U. Çevik, H. Baltaş, A. Çelik, and E. Bacaksiz, Determination of attenuation coefficients, thicknesses and effective atomic numbers for CuInSe2 semiconductor, Nucl. Instrum. Methods Phys. Res. B 247, 2006, 173-179.

[7] H. Baltaş, Ş. Çelika, U. Cevik, and E. Yanmaz, Measurement of mass attenuation coefficients and effective atomic numbers for MgB2 superconductor using X-ray energies, Radiat. Meas. 42, 2007, 55-60.

[8] B.V.T Rao, M.L.N Raju, K.L Narasimham, K. Parthasaradhi, B.M Rao, Interaction of low energy photons with biological materials and effective atomic numbers, Med Phys. 12,1985,745-8.

[9] G.S Bhandal, K Singh, Effective atomic number studies in different biological samples for partial and total photon interactions in the energy range $1 \mathrm{keV}$ to $100 \mathrm{GeV}$, Appl Radiat Isot, 44,1993,505-10.

[10] T.K Kumar, K.V Reddy, Effective atomic number for materials of dosimetric interest, Radiat Phys Chem .50,1997,545-53.

[11] Shivaramu and V. Ramprasath, Effective atomic numbers for photon energy absorption and energy dependence of some thermoluminescent dosimetric compounds, Nucl. Instrum. Methods Phys. Res. B 168, 2000, 294-304.

[12] Shivaramu, R. Vijayakumar, and L. Rajasekaran, Effective atomic numbers for photon energy absorption of some low-Z substances of dosimetric interest, Radiat. Phys. Chem. 62, 2001, 371-377.

[13] Shivaramu, Effective atomic numbers for photon energy absorption and photon attenuation of tissues from human organs, Med Dosim 27,2002,1-9.

[14] S.R. Manohara and S. M. Hanagodimath, Effective atomic numbers for photon energy absorption of essential amino acids in the energy range $1 \mathrm{keV}$ to $20 \mathrm{MeV}$, Nucl. Instrum. Methods Phys. Res. B 264, 2007, 9-14.

[15] J.H Hubbell, Review of photon interaction cross section data in the medical and biological context, Phys Med Biol 44, 1999, R1R22

[16] L. Gerward, N. Guilbert, K.B. Jensen, H. Levring, X-ray absorption in matter. Reengineering XCOM, Radiat. Phys. Chem. 60(1-2), 2001, 23-24. 